\title{
An improved estimation of the poleward expansion of coral habitats based on the inter-annual variation of sea surface temperatures
}

\author{
S. Takao' ${ }^{1}$ H. Yamano ${ }^{2}$ - K. Sugihara ${ }^{2}$ N. H. Kumagai ${ }^{2} \cdot$ M. Fujii ${ }^{1} \cdot$ \\ Y. Yamanaka ${ }^{1}$
}

Received: 12 December 2014/Accepted: 3 September 2015/Published online: 11 September 2015

(c) The Author(s) 2015. This article is published with open access at Springerlink.com

\begin{abstract}
The poleward expansion of coral habitats has been observed along the Japanese coast since the 1930s. Previous modeling studies have projected a poleward expansion using decadal-mean sea surface temperatures (SSTs) in the coldest months. However, this poleward expansion could be affected by the inter-annual variation of SST in the coldest months, which has not been considered before. In this study, the simulated pattern of poleward expansion was compared between cases where coral mortality was considered based on the inter-annual variation of SST and the decadal-mean SST in the coldest months. Modeled monthly mean SSTs for historical and future global warming simulations from the most recent climate projection model (MIROC4h) were used. The poleward expansion of corals simulated by considering mortality based on the inter-annual variation of SST in the coldest months better reproduced the observed poleward expansion speed compared to the simulations without such a consideration. Our results show the importance of considering coral mortality based on the inter-annual variation of seawater temperature to produce a more realistic poleward expansion of coral habitats.
\end{abstract}

Communicated by Biology Editor Prof. Brian Helmuth

S. Takao

takao@ees.hokudai.ac.jp

1 Faculty of Environmental Earth Science, Hokkaido University, North 10 West 5, Kita-ku, Sapporo, Hokkaido 060-0810, Japan

2 Center for Environmental Biology and Ecosystem Studies, National Institute for Environmental Studies, 16-2 Onogawa, Tsukuba, Ibaraki 305-8506, Japan
Keywords Poleward expansion - Coral reefs · Future projection - Global warming $\cdot$ Inter-annual variation $\cdot$ Sea surface temperature

\section{Introduction}

Zooxanthellate scleractinian corals (hereafter corals) provide essential habitats and energy for thousands of associated organisms and are also valuable resources for tourism (e.g., Moberg and Folke 1999). Therefore, any shift in their distribution due to climate change could have major implications for biodiversity, ecological function, biogeochemical cycling, and human society. The distributional limits of marine species are closely related to their limits of thermal tolerance (Sunday et al. 2012), and both extremely high and low seawater temperatures could affect the distribution of suitable habitats for corals (Saxby et al. 2003; Hoegh-Guldberg et al. 2005). Rising seawater temperatures due to global warming have enhanced the poleward expansion of coral habitats by lessening lowtemperature stress in winter in northern coral communities. Recently, Yamano et al. (2011) reported the first largescale evidence of a poleward expansion of corals, based on 80 years of national records from the temperate areas of Japan. The rate of this expansion has reached up to $14 \mathrm{~km} \mathrm{yr}^{-1}$, although the sporadic cooling of seawater in winter, which may cause coral bleaching and mortality, could limit the poleward expansion of corals (Saxby et al. 2003; Hoegh-Guldberg and Fine 2004; Hoegh-Guldberg et al. 2005; Nomura 2009; Yamano and Namizaki 2009). Previous field studies reported that coral bleaching with low-temperature stress could happen within several days in the southern Great Barrier Reef (Hoegh-Guldberg et al. 2005) to one month around Japan (Yamano and Namizaki 
2009), while laboratory experiments showed that coral bleaching occurred after brief (12-18 h) exposure at low temperatures (Saxby et al. 2003). These studies indicated that low-temperature exposure for several days to 1 month would lead to coral bleaching, and this would constrain new coral settlement beyond the distributional limits.

Japan is uniquely suited for assessing the poleward expansion of corals due to climate change for several reasons. First, Japan extends across a wide latitudinal range, covering subtropical to temperate areas (Fig. 1), and the latitudinal limits of coral reefs and coral distributions have been reported around the Japanese islands (Veron and Minchin 1992; Yamano et al. 2012). Second, the Japanese islands form an almost continuous chain, with subtropical and temperate corals able to inhabit the extent of the latitudinal gradient, due to the warm Kuroshio Current and its branches (Fig. 1; Veron and Minchin 1992; Sugihara et al. 2009). Third, seawater temperatures have been rising more rapidly around Japan than in most of the other oceans in the world (Japan Meteorological Agency 2013). The average SSTs around Japan have risen by $+1.08{ }^{\circ} \mathrm{C}$ per century from 1891 to 2012, which is twice the corresponding value for the world's oceans $\left(+0.51{ }^{\circ} \mathrm{C}\right.$ per century). Finally, corals around Japan have been monitored and documented periodically since the early twentieth century (Yamano et al. 2011), providing a much-needed baseline against

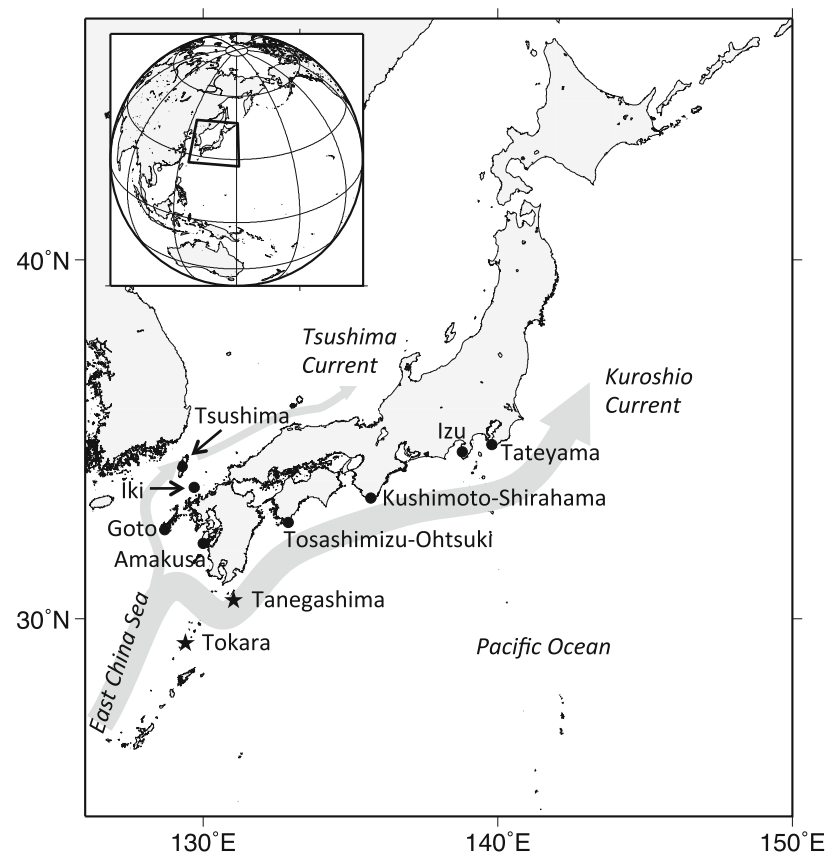

Fig. 1 Location of the study sites around Japan where on-site monitoring of the poleward expansion of coral habitats was conducted (eight sites, dots) or has subsequently been examined (two sites, stars). Gray arrows indicate the paths of the Kuroshio and Tsushima Currents which to assess the impacts of changes in seawater temperatures on their distribution.

Many studies have projected the future impacts of rising seawater temperatures on coral habitats using high- and/or low-temperature stress indices (Donner et al. 2007; Donner 2009; Teneva et al. 2012; van Hooidonk et al. 2013; Yara et al. 2009, 2011, 2012, 2014). Most studies have used a high-temperature stress index such as degree heating months, which is calculated from positive anomalies relative to mean water temperatures in the warmest months, to project the area and frequency of coral bleaching in several regions (Donner et al. 2007; Donner 2009; Teneva et al. 2012; van Hooidonk et al. 2013; Yara et al. 2009, 2014). Alternatively, some studies (including this one) have used low-temperature indices, which are defined from absolute water temperature values in the coldest months, based on the current distributional limits of coral reefs and corals, and have projected a poleward expansion of coral habitats (Yara et al. 2009, 2011, 2012). Yara et al. (2011) investigated the potential future poleward expansion of three coral communities in response to rising sea surface temperatures (SSTs) along the coasts of Japan, based on decadal-mean SSTs in the coldest months obtained from multiple climate models and simplified indices of poleward expansion. However, the estimated decadal-mean speeds of coral expansion were one order smaller than those reported by Yamano et al. (2011). As discussed in Yara et al. (2011), the discrepancy in the rate of coral expansion between the two studies was presumably caused by differences in the coral taxa selected for study. However, the poleward expansion of coral habitats could be affected by inter-annual variation of SST in the coldest months, which was not considered in Yara et al. (2011), who rather considered the decadal-mean variation of SST. This concept is described in Fig. 2, which compares coral mortality based on interannual and decadal-mean variations of SST. By considering the inter-annual variation of SST, the poleward expansion of coral habitats could be limited due to coral mortality caused by the sporadic cooling of seawater in winter (Fig. 2a). Alternatively, by considering only the decadal-mean variation of SST, such sporadic cooling events could be missed (Fig. 2b). These missing sporadic cooling events would permit corals to stay at relatively high latitude without coral mortality in winter and would lead to a slower rate of poleward expansion than the actual rate. Thus, to obtain a more realistic representation of the poleward expansion of corals, we may need to simulate the poleward expansion of corals by considering coral mortality based on the inter-annual variation of SST in the coldest months.

In this study, to minimize the influence of differences in selected coral taxa on simulations of the poleward expansion of corals, we focused on the specific coral species 

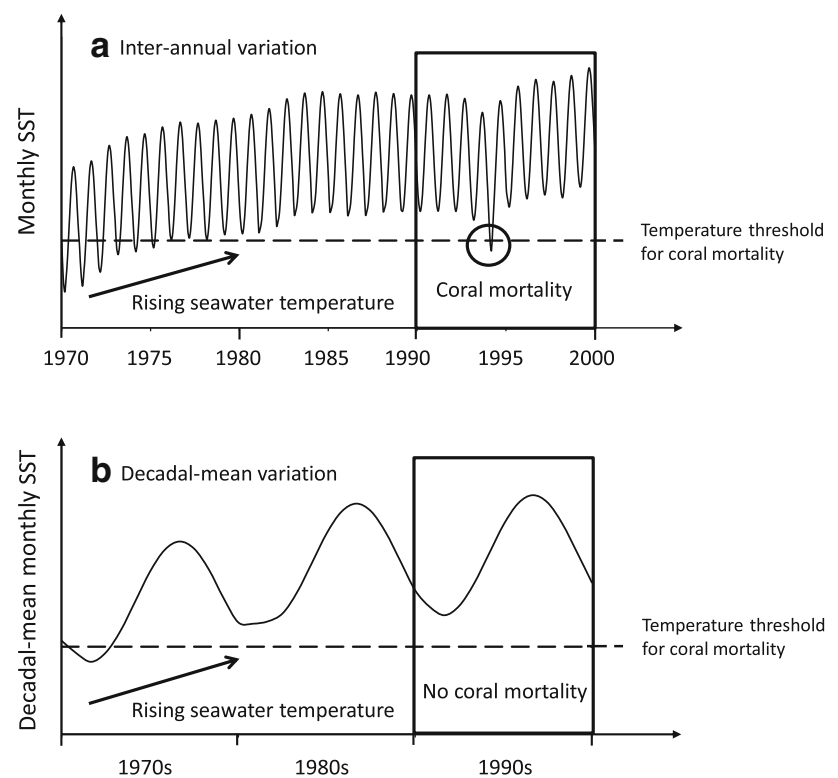

Fig. 2 Conceptual view of coral mortality based on a inter-annual and b decadal-mean variations of sea surface temperature (SST). Dotted horizontal lines indicate a temperature threshold for coral mortality in the coldest months

selected in Yamano et al. (2011) that were representative of subtropical and warm temperate regions, rather than the coral communities described in Yara et al. (2011). Furthermore, we compared the simulated patterns of poleward expansion by considering coral mortality based on the inter-annual variation of SST and decadal-mean SST in the coldest months, using the most recent climate model outputs. Finally, we projected the near-future poleward expansion of coral habitats using SSTs of a climate model after validation by the comparison of the simulated patterns of poleward expansion with observed patterns reported by Yamano et al. (2011).

\section{Materials and methods}

\section{SST-based indices for the expansion of coral species}

We selected Acropora muricata and A. solitaryensis. The former is common in tropical-subtropical environments and is a key species for reef formation in the Indo-Pacific region (Hongo and Kayanne 2011), while the latter is common in subtropical-warm temperate environments (Harriott et al. 1994, 1995; Nojima and Okamoto 2008). These two species have both displayed rapid poleward expansion since the 1930s (Yamano et al. 2011).

We used monthly mean SSTs in the coldest months as temperature thresholds for coral mortality to improve the model projection, because previous studies have used the decadal-mean SST in the coldest months as indices for coral habitats (Yara et al. 2011, 2012). Monthly mean SSTs in the coldest months were calculated from observational SST data used in previous studies (Nomura 2009; Yamano and Namizaki 2009). A monthly mean SST in the coldest months below 15.1 and $13.4{ }^{\circ} \mathrm{C}$ caused bleaching and mortality of A. muricata in Kushimoto-Shirahama (Fig. 1) and A. solitaryensis in Tateyama (the most southeastern point of the Boso Peninsula), respectively. Monitoring of SST and coral communities since 2008 (http://db.cger.nies. go.jp/gem/en/coral/) has confirmed that A. muricata appears in the southern area of Goto (Fig. 1), where the monthly mean SST in the coldest months is higher than $15.8^{\circ} \mathrm{C}$, while it has not been found in other areas of Goto and Amakusa (Fig. 1), where the monthly mean SSTs in the coldest months are below 15.3 and $15.1{ }^{\circ} \mathrm{C}$, respectively. Thus, we defined the potential northern limit of a suitable habitat for A. muricata as the area where the monthly mean SST in the coldest months is higher than $15.8^{\circ} \mathrm{C}$ every year. Therefore, when the monthly mean SST in the coldest months falls below the threshold $\left(15.8{ }^{\circ} \mathrm{C}\right)$ just once within a given period (e.g., $10 \mathrm{yr}$ ) as shown in Fig. 2a, A. muricata cannot establish a community due to coral mortality caused by low-temperature stress. Acropora solitaryensis appears in some areas of Izu (the southernmost and easternmost point of Izu Peninsula) and Tateyama (Fig. 1), where the monthly mean SST in the coldest months is higher than $14.0^{\circ} \mathrm{C}$. On the other hand, it is not found in Iki and Tsushima (Fig. 1), where the monthly mean SSTs in the coldest months are below 13.2 and $13.3{ }^{\circ} \mathrm{C}$, respectively. Thus, the potential northern limit of the suitable habitat for A. solitaryensis was defined as the area where SST in the coldest months is higher than $14.0^{\circ} \mathrm{C}$ every year in this study. Based on the temperature thresholds described above, algorithms for calculating the suitable habitat estimated from coral mortality with and without the consideration of the inter-annual variation of SST in the coldest months are as follows:

$$
\begin{aligned}
& \mathrm{SHI}_{i, j, Y}=\min \mathrm{SST}_{i, j, Y}-T_{\mathrm{thr}} \\
& P_{i, j}=1 \quad\left(\text { minimum } \operatorname{SHI}_{i, j, Y}>0\right) \\
& P_{i, j}=0 \quad \text { (minimum } \mathrm{SHI}_{i, j, Y} \leqq 0 \text { ), } \\
& \overline{\mathrm{SHI}}_{i, j}=\frac{1}{Y_{2}-Y_{1}} \sum_{Y=Y_{1}}^{Y_{2}} \min \mathrm{SST}_{i, j, Y}-T_{\mathrm{thr}} \\
& P_{i, j}^{\prime}=1 \quad\left(\overline{\mathrm{SHI}}_{i, j}>0\right) \\
& P_{i, j}^{\prime}=0 \quad\left(\overline{\mathrm{SHI}}_{i, j} \leqq 0\right)
\end{aligned}
$$

where $S H I$ and $\overline{S H I}$ are the suitable habitat index with and without the consideration of coral mortality based on the inter-annual variation of SST, respectively; min SST is the monthly mean SST in the coldest months; $T_{\text {thr }}$ is the 
temperature threshold for coral mortality in the coldest months $\left(15.8^{\circ} \mathrm{C}\right.$ for A. muricata and $14.0{ }^{\circ} \mathrm{C}$ for A. solitaryensis), respectively; subscripts $i$ and $j$ are the number of longitudinal and latitudinal grids, respectively; $Y$ is the number of years of a climate model used in this study; $Y_{1}$ and $Y_{2}$ are the starting and end points for calculating the suitable habitat, respectively; $P$ and $P^{\prime}$ mean the presence of corals $(1=$ present, $0=$ absent $)$ with and without the consideration of coral mortality based on the inter-annual variation of SST within a given period (e.g., $10 \mathrm{yr}$ ), respectively. In Eq. (1), the minimum $S H I_{i, j, Y}$ indicates a minimum value from the year $Y_{1}$ to $Y_{2}$.

\section{Datasets of modeled sea surface temperatures}

Monthly mean SSTs from a high-resolution climate model, MIROC4h (Sakamoto et al. 2012), were used to simulate the poleward expansion of corals using the SST-based indices described above. This model is one of the most recent climate models developed in the Coupled Model Intercomparison Project phase 5 (CMIP5; Taylor et al. 2012) with a future emission scenario based on the Representative Concentration Pathways (RCPs; Moss et al. 2010) and is used in the Fifth Assessment Report of the Intergovernmental Panel on Climate Change (IPCC AR5; Stocker et al. 2013). Although the future projection of MIROC4h has only been calculated up to 2035 with the RCP4.5 simulation, the model has the highest horizontal resolution for oceanic components $\left(0.28125^{\circ} \times 0.1875^{\circ}\right)$ among the CMIP5 models. Furthermore, there are many improvements within MIROC4h compared with the previous model used in Yara et al. (2011). For example, although there were biases in SST in the previous model (i.e., cold at low and mid latitudes and warm at high latitudes), these errors have been significantly reduced in MIROC4h (Sakamoto et al. 2012). We used the historical simulation from 1950 to 2005 and the global warming projection from 2006 to 2029 under the RCP4.5 simulation. The RCPs (RCP2.6, RCP4.5, RCP6.0, and RCP8.5) will lead to radiative forcing levels of 2.6, 4.5, 6.0, and $8.5 \mathrm{~W} \mathrm{~m}^{-2}$, respectively, by the end of the twenty-first century, with the globally averaged mole fractions of atmospheric $\mathrm{CO}_{2}$ reaching 421, 538, 670, and $936 \mathrm{ppm}$, respectively (van Vuuren et al. 2011). However, there is little difference in the radiative forcing level from 2006 to 2029 among all the RCP simulations (van Vuuren et al. 2011).

Because there are generally biases in climate model results, we corrected them in the monthly mean SSTs from the MIROC4h using observed monthly data provided by the National Oceanic and Atmospheric Administration (NOAA) Optimum Interpolation SST (OISST) version 2 (NOAA, Boulder, CO, USA; http://www.esrl.noaa.gov/ psd/; Reynolds et al. 2007), for the period from September 1981 to the present. Although the OISST data were composed of SSTs obtained from in situ measurements as well as satellite-derived SST data, many modeling studies have also regarded them as observed SSTs (Yara et al. 2011, 2014; van Hooidonk et al. 2013). The bias-correction procedure was detailed in Yara et al. (2009, 2011, 2014). Briefly, we first calculated the monthly mean SST anomalies for the period of 1950-2029 (960 months) in the historical and RCP4.5 simulations relative to the monthly mean climatology data (the 20-yr mean SST from 1986 to 2005) in the historical simulation. Second, the calculated monthly SST anomalies for each year over the period of 1950-2029 (monthly data for $80 \mathrm{yr}$ ) were added to the monthly mean value of the OISST 1986-2005 climatology data (monthly data) and interpolated to the horizontal resolution of MIROC4h using the nearest neighbor method. Finally, the SST in the coldest months of each year was calculated from the bias-corrected SSTs for the period spanning 1950-2029. To assess the reproducibility of the modeled SSTs from MIROC4h, we compared the mean and minimum values of observed SSTs (OISST data) with the bias-corrected SSTs in the coldest months during the past two periods (1988-1995 and 1999-2010) in the ten study sites (Fig. 1). The two periods were selected based on Yamano et al. (2011). The reproducibility of the modeled SST was assessed using the root-mean-square error (RMSE) and mean normalized bias (MNB), which were calculated as follows:

RMSE $=\sqrt{\frac{1}{n} \sum_{i=1}^{n}\left(M_{i}-I_{i}\right)^{2}}$,
$\operatorname{MNB}(\%)=\frac{1}{n} \sum_{i=1}^{n}\left(\left(M_{i}-I_{i}\right) / I_{i}\right) \times 100$

where $M_{i}$ is the modeled SST, $I_{i}$ is the observed value, and $n$ is the number of samples. In this study, the poleward expansion of corals was simulated using modeled SSTs in grids with a depth shallower than $200 \mathrm{~m}$ (coastal areas; Pernetta and Milliman 1995). However, two out of ten available modeled grids near the study sites in Fig. 1 (Izu and Tateyama) were located offshore (deeper than $200 \mathrm{~m}$ ). At the two sites, the nearest available grid data $( \pm 1$ grid $)$ close to the sites were assumed to be the same as the coastal ones and were used to maximize the available data and allow a comparison with observed chronological changes in coral habitats.

\section{Model evaluation}

To evaluate the timing of the poleward expansion of suitable habitats for the two coral species simulated using the 
SSTs in the coldest months, the results were compared with the observed chronological changes at eight sites around Japan (Yamano et al. 2011; Fig. 1). To quantitatively assess the improvement in the simulation of poleward expansion by considering coral mortality based on the inter-annual variation of SST in the coldest months, we compared the results obtained in this study with simulations using the average SST in the coldest months during a given period (the method used by Yara et al. 2011, 2012). Statistical metrics used to assess each model's performance are summarized in Tables 1 and 2. Each model's performance was assessed using correct prediction rate (which assesses agreement between the observed and simulated results) and the area under the receiver operating characteristic curve (AUC). The receiver operating characteristic curve is sensitivity (rate of true positive projection) as a function of 1 minus specificity (specificity is the rate of true negative projection). The AUC provides a single value representing model accuracy, and AUC values closer to 1 indicate a better fit between the observed and simulated results (Liu et al. 2011; Jueterbock et al. 2013; Takao et al. 2015). We also assessed each model's performance using the true skill statistic (TSS), which is calculated from sensitivity and specificity (TSS $=$ sensitivity + specificity -1 ). TSS values closer to 1 indicate a better positive correlation between the observed and simulated results, and the value of 0 indicates no correlation (Allouche et al. 2006; Liu et al. 2011).

\section{Results}

\section{Comparisons between observed and modeled SST}

Figure 3 shows comparisons of the mean and minimum values of the observed SSTs (OISST) with those of modeled SSTs in the coldest months during the past two periods (1988-1995 and 1999-2010). The observed SSTs were obtained at the ten sites shown in Fig. 1. The mean and minimum values of modeled SSTs were in good agreement

Table 1 Confusion matrix used to assess model performance, where $N_{i j}$ indicates the number of sites (class $i$ for observation and class $j$ for simulation)

\begin{tabular}{lll}
\hline & Observed & \\
\cline { 2 - 3 } & Presence & Absence \\
\hline Simulated & $N_{11}$ & $N_{01}$ \\
Presence & $N_{10}$ & $N_{00}$ \\
Absence &
\end{tabular}

Class 0 is absence, and class 1 is presence, respectively
Table 2 Summary of statistical indices and formulae used in this study: area under a receiver operating characteristic curve (AUC); true skill statistics (TSS); agreement rate between the observation and the simulation (correct); rate of true positive projection (sensitivity); rate of true negative projection (specificity); and rate of false negative projection (1-specificity)

\begin{tabular}{ll}
\hline Index & Formula \\
\hline AUC & $\frac{\text { Sensitivity } \times(1-\text { Specificity })+(1+\text { Sensitivity }) \times \text { specificity }}{2}$ \\
TSS & Sensitivity + specificity -1 \\
Correct & $\frac{N_{11}+N_{00}}{N_{11}+N_{01}+N_{10}+N_{00}}$ \\
Sensitivity & $\frac{N_{11}}{N_{11}+N_{10}}$ \\
Specificity & $\frac{N_{00}}{N_{01}+N_{00}}$ \\
1-specificity & $\frac{N_{01}}{N_{01}+N_{00}}$ \\
\hline
\end{tabular}

See Table 1 for the explanation of $N$
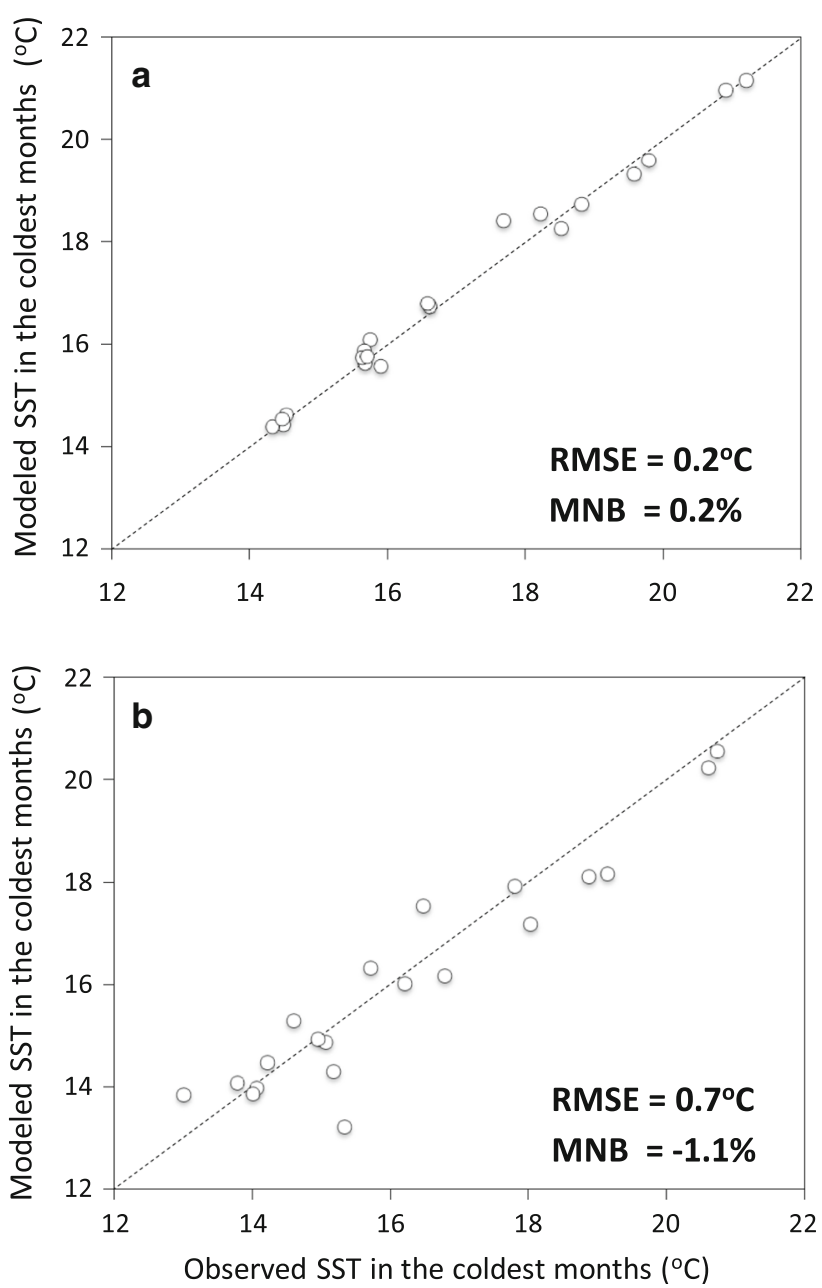

Fig. 3 Comparisons of a mean and b minimum observed (OISST) and modeled (MIROC4h) monthly SSTs in the coldest months during the past two periods (1988-1995 and 1999-2010) at the ten study sites as shown in Fig. 1. The dashed line indicates the 1:1 line 
with those of observed SSTs at these sites $(n=20$, $\mathrm{RMSE}=0.2$ and $0.7{ }^{\circ} \mathrm{C}, \quad \mathrm{MNB}=0.2$ and $-1.1 \%$, respectively).

\section{Timing of the poleward expansion of coral habitats}

Figure 4 shows a comparison of the changes in the occurrence of A. muricata reported by Yamano et al. (2011) with the simulated changes using the bias-corrected
SSTs in the coldest months from MIROC4h, with and without the consideration of coral mortality based on the inter-annual variation of SST. The timing of the poleward expansion of A. muricata, especially in the Pacific Ocean regions, was simulated well by considering the inter-annual variation of SST (Fig. 4). In the East China Sea, our results with the consideration of coral mortality based on the interannual variation of SST were relatively well simulated compared to those without the consideration (Fig. 4a),
Fig. 4 Simulated changes in the occurrence of Acropora muricata at the eight study sites in Fig. 1, by considering coral mortality based on a the average SST value in the coldest months during a given period (the method used by Yara et al. 2011, 2012) and b the interannual variation of SST in the coldest months. The actual change reported by Yamano et al. (2011) is shown in $\mathbf{c}$ for reference. For A. muricata, the previous limit of the northern distribution in the East China Sea (Tokara and Tanegashima) is indicated. Numbers indicate minimum estimates of poleward expansion speed $\left(\mathrm{km} \mathrm{yr}^{-1}\right)$. "Possibly present" means that more than two candidate species names, including the species of interest, were suggested based on Yamano et al. (2011)

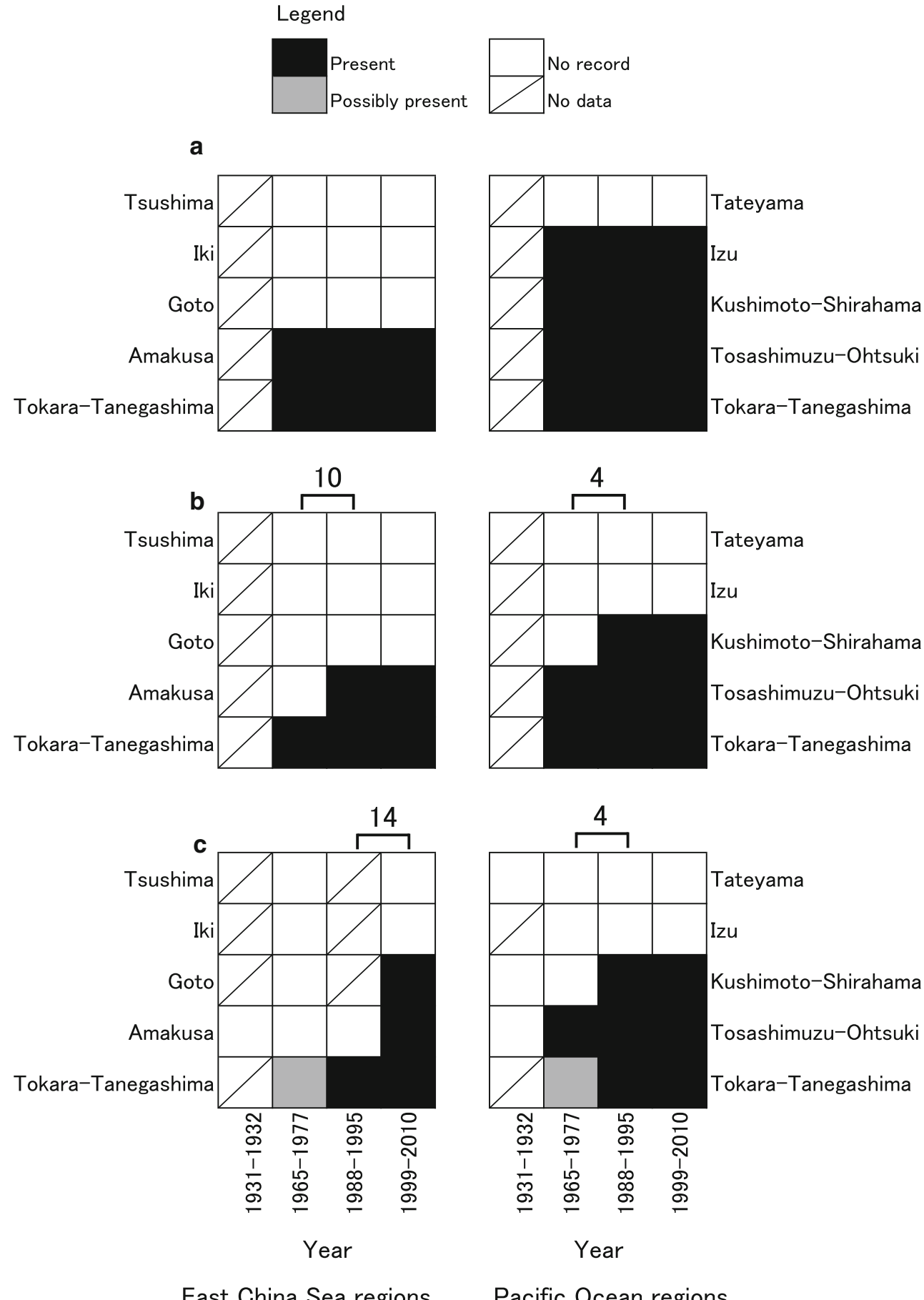

East China Sea regions
Pacific Ocean regions 
Table 3 Model performance evaluated by area under a receiver operating characteristic curve (AUC); true skill statistics (TSS); agreement rate between the observation and the simulation (correct); rate of true positive projection (sensitivity); and rate of true negative projection (specificity) for simulating poleward expansion of suitable habitats of Acropora muricata and A. solitaryensis by previous method and this study

\begin{tabular}{lllll}
\hline & \multicolumn{2}{l}{ Acropora muricata (Fig. 4) } & & \multicolumn{2}{l}{ A. solitaryensis (Fig. 5) } \\
\cline { 2 - 3 } & Previous method & This study & Previous method & 0.622 \\
\hline AUC & 0.785 & 0.932 & 0.500 & 0.244 \\
TSS & 0.570 & 0.864 & 0.000 & 0.667 \\
Correct & 0.767 & 0.933 & 0.375 & 0.800 \\
Sensitivity & 0.923 & 0.923 & 1.000 & 0.444 \\
Specificity & 0.647 & 0.941 & 0.000 & This study \\
\hline
\end{tabular}

Previous method is the simulation using the average SST in the coldest months during a given period (Yara et al. 2011, 2012)

although the simulated timing of the poleward expansion was nearly a decade earlier than that reported by Yamano et al. (2011). We found that both the AUC and TSS obtained from the simulated changes in the occurrence of A. muricata with the consideration of coral mortality based on the inter-annual variation of SST were higher than those without the consideration (Table 3).

For A. solitaryensis, both the AUC and TSS values improved (Table 3). The simulation in the East China Sea with the consideration of coral mortality based on the interannual variation of SST reproduced the timing of poleward expansion reported by Yamano et al. (2011) relatively well compared to the simulation without the consideration (Fig. 5). The poleward expansion of A. solitaryensis in the Pacific Ocean was not reproduced, regardless of the consideration of coral mortality based on the inter-annual variation of SST in the coldest months.

\section{Changes in the potential northern limits of coral habitats}

Changes in the potential northern limits of coral habitats for A. muricata and A. solitaryensis from the 1950s to 2020s are shown in Figs. 6 and 7, respectively. The potential northern limits of suitable habitats for the two species were estimated by considering the effect of the inter-annual variation of SST on coral mortality (blue squares) to simulate the poleward expansion during the period. The blue squares in Figs. 6 and 7 overlap with the red squares, which represent the differences in potential habitats estimated by considering coral mortality based on the inter-annual variation of SST and decadal-mean SST in the coldest months. Thus, the potential northern limits were located at lower latitudes than estimated in previous studies using the decadal-mean SST in the coldest months (red squares; Yara et al. 2011, 2014).

When we considered the effects of the inter-annual variation of SST in the coldest months on coral mortality, the simulated position of the northern limit of the suitable habitat for A. muricata moved northward from $32.0^{\circ} \mathrm{N}$ to $32.7^{\circ} \mathrm{N}$ in the East China Sea (Fig. 8a) and from $32.7^{\circ} \mathrm{N}$ to $35.2^{\circ} \mathrm{N}$ in the Pacific Ocean (Fig. 8b) over the 70-yr period from the 1950s to 2020s. The simulated northern limit position from the 1950 s to the 2020 s, without considering the effects of the inter-annual variation of SST in the coldest months on coral mortality, moved from $32.7^{\circ} \mathrm{N}$ to $33.5^{\circ} \mathrm{N}$ and from $35.2^{\circ} \mathrm{N}$ to $35.5^{\circ} \mathrm{N}$ in the East China Sea and the Pacific Ocean, respectively. For A. solitaryensis, the simulated northern limit position from the 1950s to the 2020s, with and without considering the effects of the interannual variation of SST in the coldest months on coral mortality, moved from $34.2^{\circ} \mathrm{N}$ to $35.0^{\circ} \mathrm{N}$ and from $34.6^{\circ} \mathrm{N}$ to $35.3^{\circ} \mathrm{N}$, respectively, in the East China Sea (Fig. 8c), and from $33.7^{\circ} \mathrm{N}$ to $35.9^{\circ} \mathrm{N}$ and from $35.9^{\circ} \mathrm{N}$ to $36.5^{\circ} \mathrm{N}$, respectively, in the Pacific Ocean (Fig. 8d).

\section{Discussion}

The principal objective of this study was to determine whether the simulated poleward expansion of coral habitats was better reproduced by considering the effects of the inter-annual variation of seawater temperatures in the coldest months on coral mortality (Fig. 2). In this study, the poleward expansion of corals was simulated after assessing the reproducibility of the modeled SSTs in the coldest months obtained from MIROC4h by comparing them with observed SSTs (OISST). We assessed the reproducibility of the modeled SSTs based on the mean and minimum values during the past two periods (1988-1995 and 1999-2010). Although even the most recent climate models have difficulties in reproducing monthly mean SST values in the same year, the MIROC4h can reproduce the sporadic cooling of seawater in winter within a given period (e.g., $10 \mathrm{yr}$ ), if not in the same year (Fig. 9). As shown in Eq. 1, our model based on the inter-annual variation of 


\section{Legend}
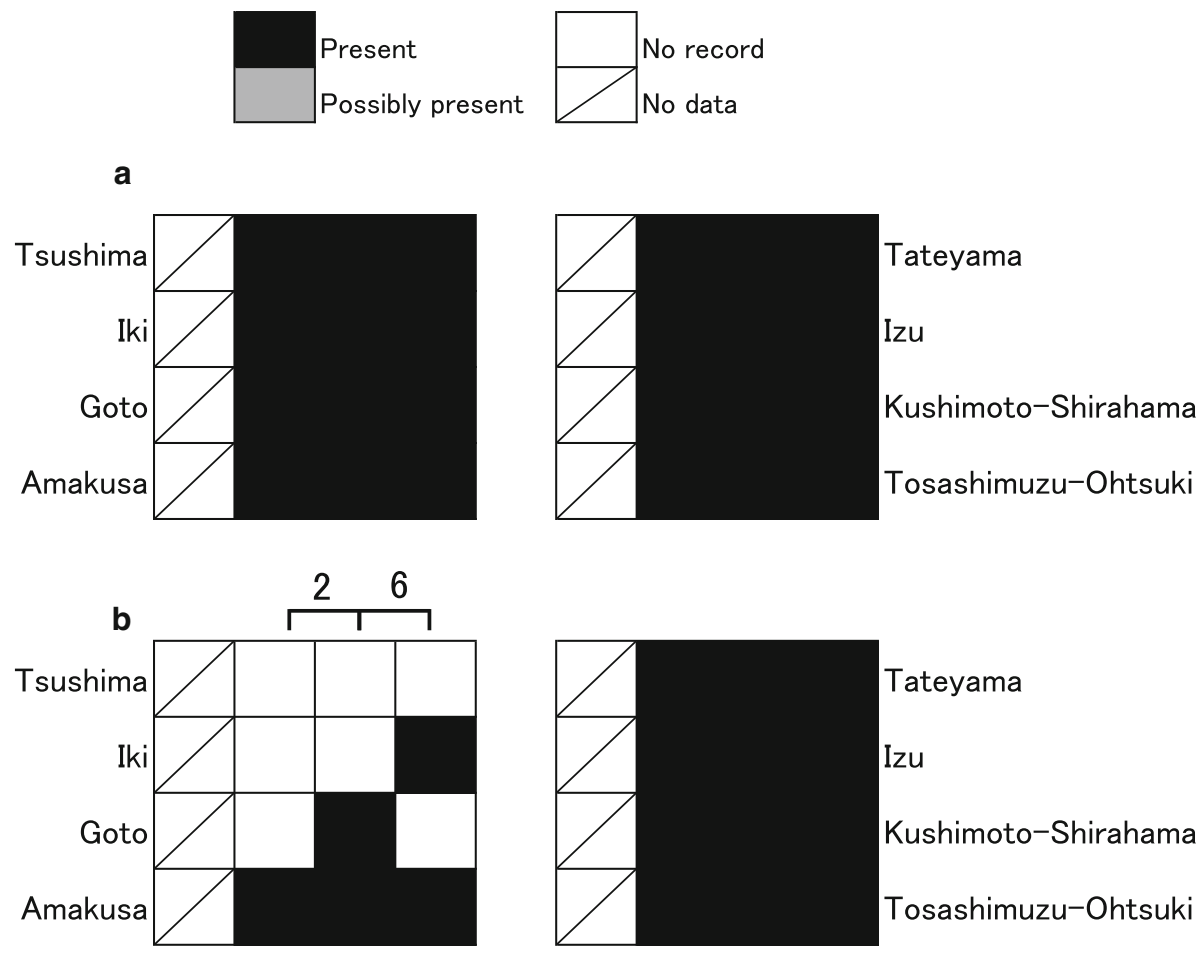

Tateyama

Izu

Kushimoto-Shirahama

Tosashimuzu-Ohtsuki
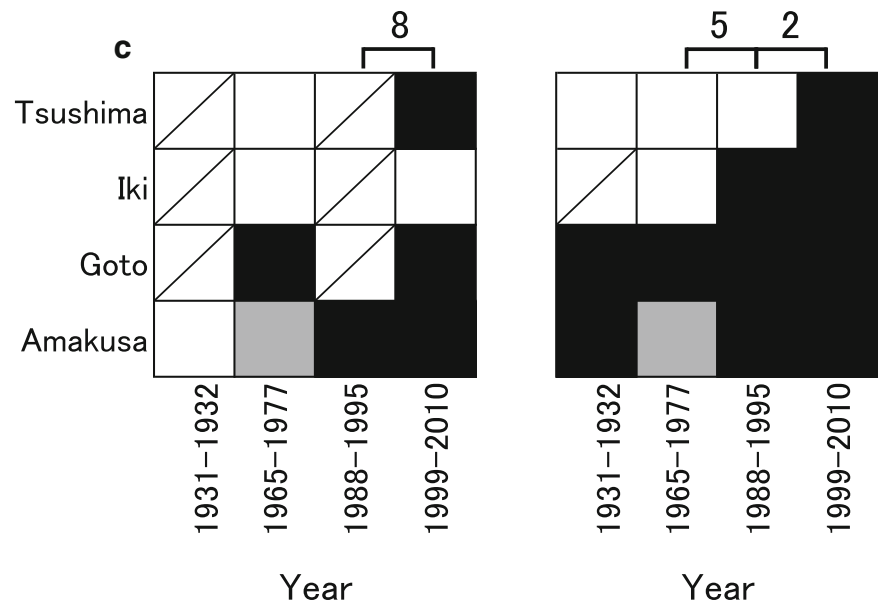

Tateyama

Izu

Kushimoto-Shirahama

Tosashimuzu-Ohtsuki

\section{East China Sea regions}

\section{Pacific Ocean regions}

Fig. 5 Simulated changes in the occurrence of Acropora solitaryensis at the eight study sites in Fig. 1, by considering coral mortality based on a the average SST value in the coldest months during a given period (the method used by Yara et al. 2011, 2012) and $\mathbf{b}$ the interannual variation of SST in the coldest months. The actual change

SST does not necessarily require the complete reproducibility of monthly mean SST values in the same year. By considering the difficulties mentioned above, our model needs the reproducibility of the minimum values of monthly mean SST within a given period. The RMSE values obtained from the comparisons for the mean and minimum SSTs were 0.2 and $0.7{ }^{\circ} \mathrm{C}$, respectively (Fig. 3). reported by Yamano et al. (2011) is shown in $\mathbf{c}$ for reference. Numbers indicate minimum estimates of poleward expansion speed $\left(\mathrm{km} \mathrm{yr}^{-1}\right)$. "Possibly present" means that more than two candidate species names, including the species of interest, were suggested based on Yamano et al. (2011)

The MNB values were also very small (within $\pm 2 \%$ ). The results indicated a good reproducibility of the modeled SSTs in the coldest months using MIROC4h.

By considering the effects of the inter-annual variation of SST in the coldest months on coral mortality, the simulated results in this study produced a more realistic poleward expansion of coral habitats for the two species 


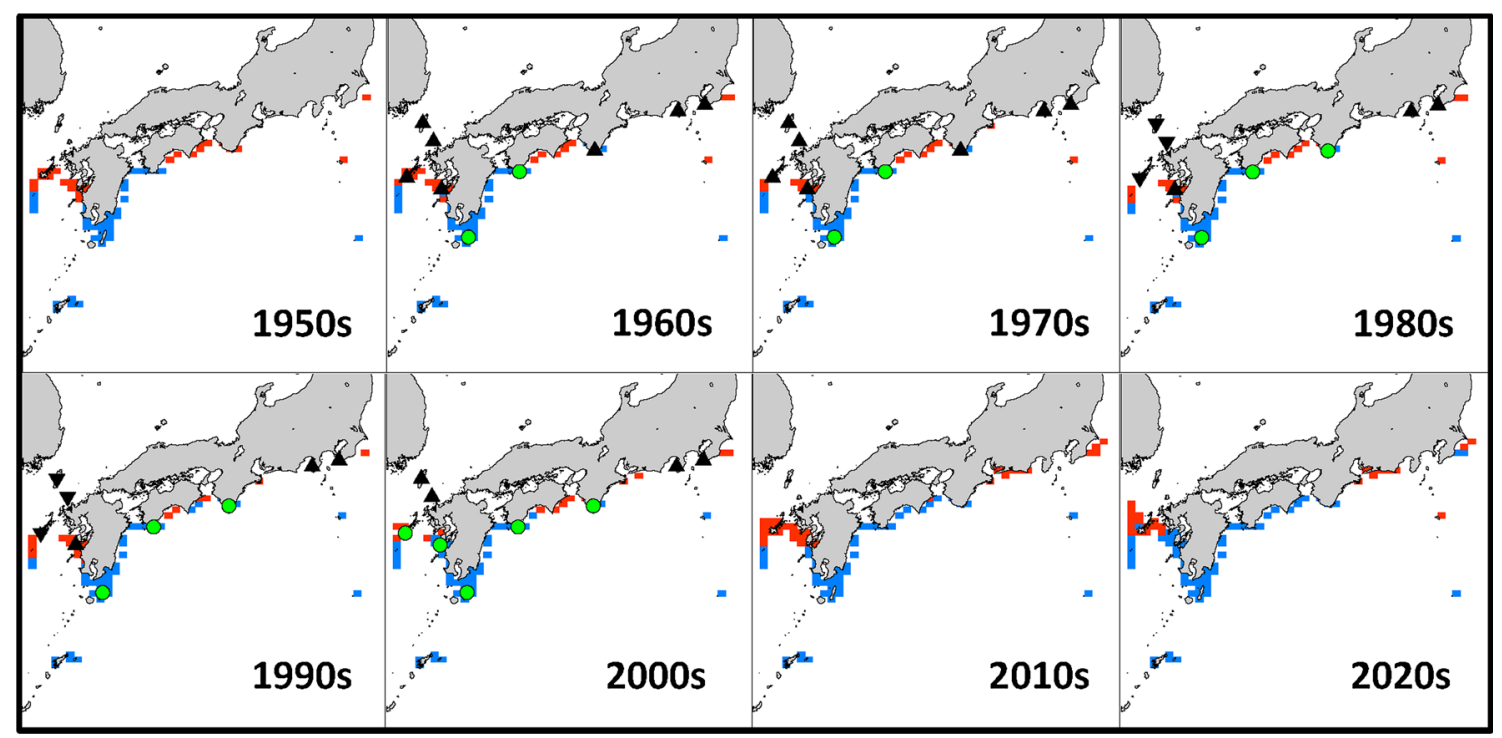

Fig. 6 Changes in the potential northern limits of suitable habitats for Acropora muricata from the 1950s to 2020s. Red squares represent the potential habitats simulated by using the decadal-mean SST in the coldest months (the method used by Yara et al. 2011, 2012). Blue squares represent the potential habitats simulated by considering coral mortality based on the inter-annual variation of SST in the coldest months. Note that some red squares are overlapped with and are hidden by blue areas. Green circles, black upward and downward triangles represent the presence, absence, and no data of $A$. muricata shown in Fig. 4c, respectively

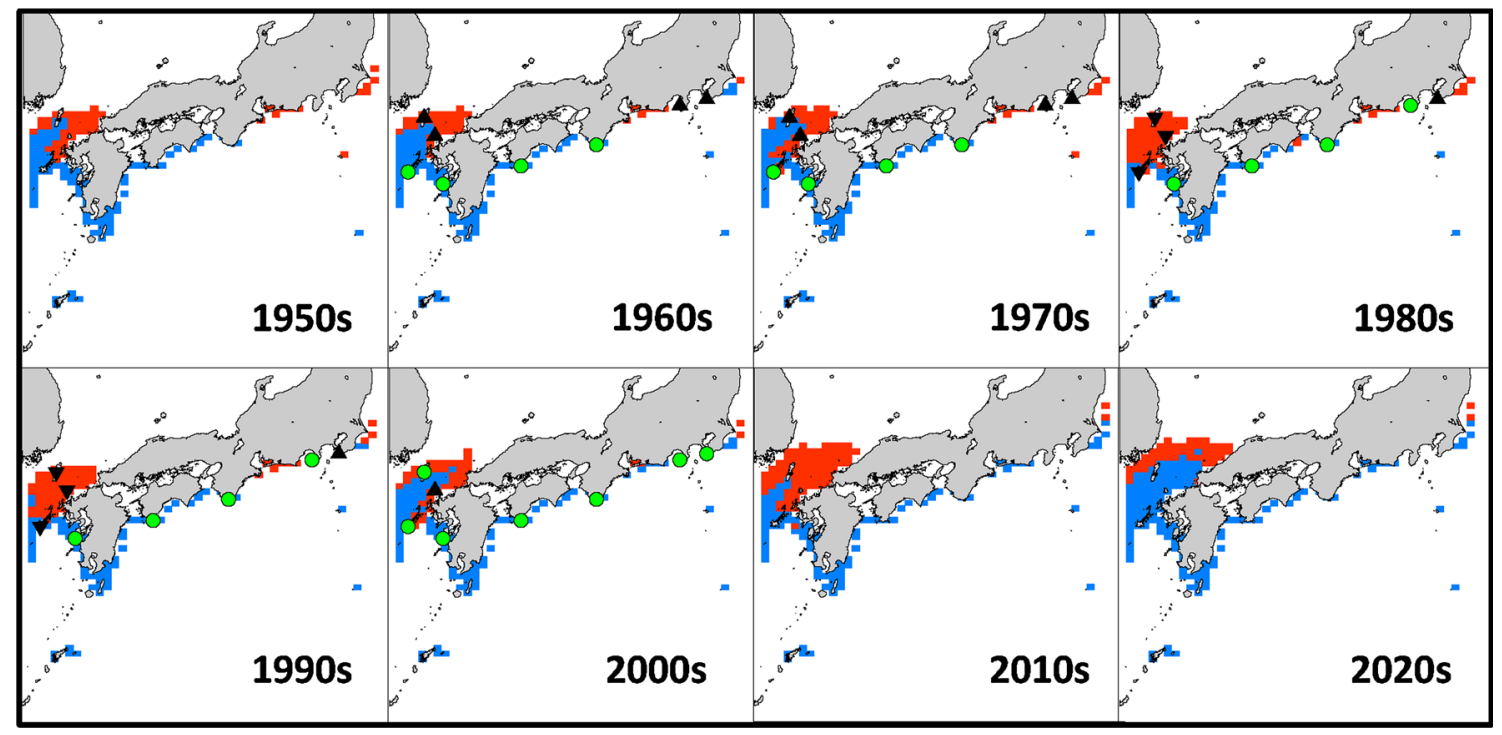

Fig. 7 Changes in the potential northern limits of suitable habitats for Acropora solitaryensis from the 1950s to 2020s. Red squares represent the potential habitats simulated by using the decadal-mean SST in the coldest months (the method used by Yara et al. 2011, 2012). Blue squares represent the potential habitats simulated by

than simulations without a consideration of these effects (Table 3; Figs. 4, 5). When we considered coral mortality based on the inter-annual variation of SST in the coldest months, the simulated minimum speeds of the poleward expansion for A. muricata produced by the model were 10 and $4 \mathrm{~km} \mathrm{yr}^{-1}$ in the East China Sea and the Pacific Ocean, respectively (Fig. 4). These estimations are comparable to considering coral mortality based on the inter-annual variation of SST in the coldest months. Note that some red squares are overlapped with and are hidden by blue areas. Green circles, black upward and downward triangles represent the presence, absence, and no data of $A$. solitaryensis shown in Fig. 5c, respectively

the speeds reported by Yamano et al. (2011) in both regions $\left(14 \mathrm{~km} \mathrm{yr}^{-1}\right.$ in the East China Sea and $4 \mathrm{~km} \mathrm{yr}^{-1}$ in the Pacific Ocean) and are more realistic than the estimated speeds without the consideration of the effects of the interannual variation of SST in the coldest months on coral mortality, which showed no poleward expansion (Fig. 4). By considering the effects of the inter-annual variation of 

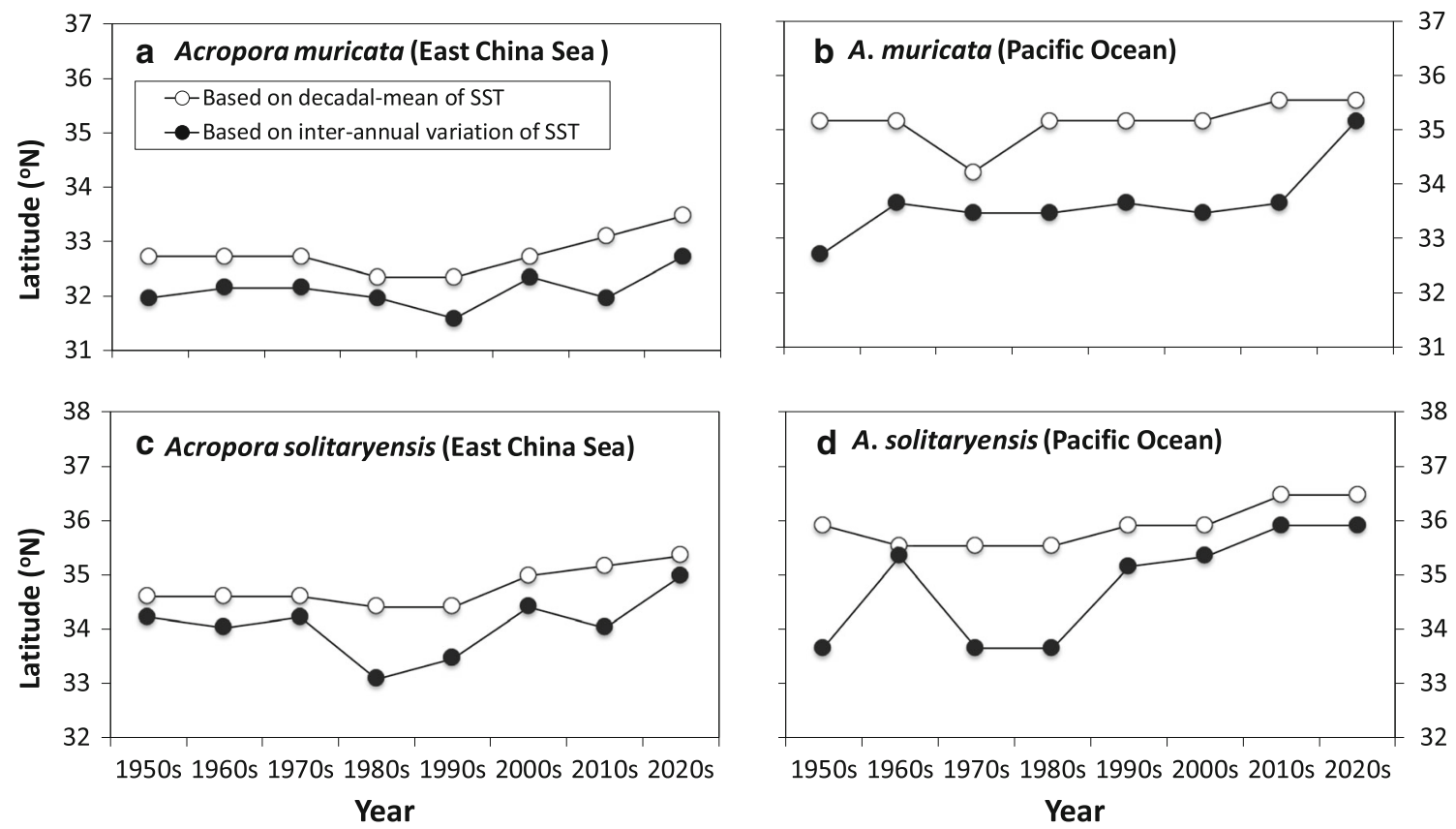

Fig. 8 Temporal changes in the position of the northern limit of the suitable habitat for A. muricata $(\mathbf{a}, \mathbf{b})$ and A. solitaryensis (c, d), in the East China Sea and Pacific Ocean

SST in the coldest months, the estimated speed of the poleward expansion of $A$. solitaryensis habitats in the East China Sea reached $6 \mathrm{~km} \mathrm{yr}^{-1}$ (Fig. 5), which is comparable with the speed $\left(8 \mathrm{~km} \mathrm{yr}^{-1}\right)$ reported by Yamano et al. (2011), although the poleward expansion of A. solitaryensis in the Pacific Ocean was not reproduced in this study. There was no poleward expansion in both regions when the effect of inter-annual variation of SST on coral mortality was not considered (Fig. 5). These results strongly suggest that a combination of a reproducible model of the inter-annual variation of seawater temperature, such as MIROC4h, and the consideration of the effects of the inter-annual variation of SST in the coldest months on coral mortality lead to a more realistic simulations of the poleward expansion of coral habitats in temperate areas of Japan, where there is a latitudinal limit of coral reefs and coral distribution.

The simulated northern limits estimated from coral mortality based on the inter-annual variation of SST in the coldest months were located at lower latitudes than those based on the decadal-mean variation of SST (Figs. 6-8). For A. muricata, the distances between these latitudes for the simulated results with and without the effect of the interannual variation of SST on coral mortality in the 2020s were approximately 84 and $42 \mathrm{~km}$ in the East China Sea and Pacific Ocean, respectively. The corresponding distances for A. solitaryensis in the 2020 s were approximately 42 and $63 \mathrm{~km}$ in each region. These results suggest that less new coral habitat could be formed around Japan due to the poleward expansion caused by a rise in water temperature than previously estimated (Yara et al. 2011, 2012).
Although the poleward expansion of A. solitaryensis in the Pacific Ocean was not reproduced in the study sites, particularly Izu and Tateyama (Fig. 5), the potential suitable habitats for A. solitaryensis expanded poleward from the 1970s to 2000s (Figs. 7, 8d). In the East China Sea, the simulated northern limits of $A$. solitaryensis retreated southward between the 1980s and 1990s and then expanded poleward in the 2000s. These results corresponded with the general pattern of the observed poleward expansion of $A$. solitaryensis in both regions (green circles in Fig. 7). The observed past range expansion of corals along Japan would be affected by the Kuroshio and Tsushima Currents (Fig. 1), which transport warm waters and potential coral larvae from south to north (Veron and Minchin 1992). Warm waters transported by the Kuroshio and Tsushima Currents could prevent coral mortality due to low-temperature conditions in winter and allow coral habitats to expand further poleward. Thus, besides the consideration of the effect of the inter-annual variation of SST in the coldest months on coral mortality, the reconstruction of current patterns, which is outside the scope of this study, might be one of the reasons why our improved simulation can reconstruct the observed poleward expansion.

In addition to coral mortality due to the sporadic cooling of seawater in winter, the dispersal rate of corals would be one of the potential limits for the poleward expansion of coral habitats. Previous studies have reported coral spawning in several regions north of $32^{\circ} \mathrm{N}$ around Japan (van Woesik 1995; Harii et al. 2001; Nozawa et al. 2006; Mezaki et al. 2007). Although there is the difficulty of 

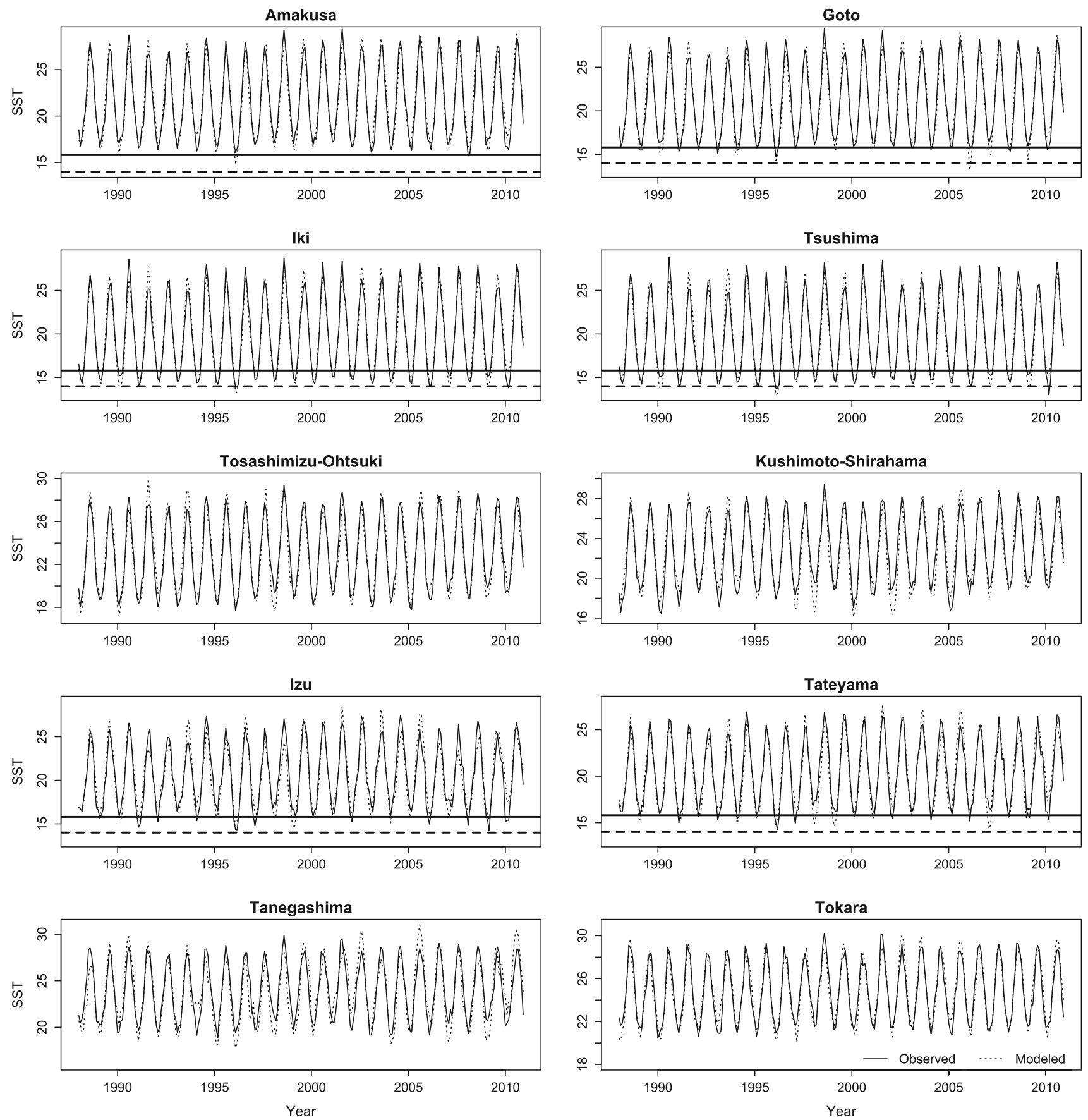

Fig. 9 Changes in observed (OISST) and modeled (MIROC4h) monthly SSTs from 1988 to 2010 in the ten study sites shown in Fig. 1. Solid and dotted horizontal lines indicate the temperature threshold for mortality of A. muricata and A. solitaryensis in the coldest months, respectively

directly measuring the dispersal rate of corals, it is known that the first larval settlement of A. muricata occurs more than $3 \mathrm{~d}$ after spawning (Nozawa and Harrison 2008). The warm Kuroshio and Tsushima Currents flow from south to north along Japan (Fig. 1) at speeds of 1-2 and $0.2-0.5 \mathrm{~m} \mathrm{~s}^{-1}$, respectively (Katoh 1994; Sugisaki et al. 2010; Ito et al. 2014). If coral larvae are carried with these currents, their dispersal rate could reach at least
$17 \mathrm{~km} \mathrm{~d}^{-1}$. In this study, thus, we assumed that the dispersal rate of corals would not be a limiting factor for the poleward expansion of coral habitats around Japan.

To obtain a more realistic representation of the poleward expansion of corals from the past to the present time (1950s-2000s), we have focused on the two concepts for the effect of SST in the coldest months on coral mortality (Fig. 2). Our results indicate that coral mortality based on 
the inter-annual variation of SST in the coldest months is a key factor for representing the poleward expansion of corals around Japan (Figs. 4, 5).

In addition to SSTs, other environmental factors, such as ocean acidification and light availability, could also affect the poleward expansion of coral habitats. Several studies have evaluated impacts of the combination of global warming and ocean acidification on corals using climate model future projections (Yara et al. 2012; van Hooidonk et al. 2014). In this study, we did not consider the effect of ocean acidification on the poleward expansion of corals from the 1950 s to the 2000 s because the change in aragonite saturation states in this period was negligible for corals (Feely et al. 2009; Ishii et al. 2011).

Recently, Muir et al. (2015) suggested that declining light availability in winter with increasing latitudes would also limit the poleward expansion of corals due to a decrease in vertically suitable habitats. The two coral species selected in this study (A. muricata and A. solitaryensis) are abundant at depths shallower than $\sim 10 \mathrm{~m}$ around Japan (Nomura 2009; Yamano and Namizaki 2009; Sugihara et al. 2015). Thus, the effect of light availability on these corals around Japan would be relatively small compared to other corals living at deeper depths.

Physiological acclimation and adaptation should also be considered. McCulloch et al. (2012) have suggested that corals with the ability to regulate their internal $\mathrm{pH}$ (i.e., $\mathrm{pH}$ up-regulation relative to ambient seawater) might counteract ocean acidification. Photosynthetic responses of corals and symbiotic zooxanthellae to low light conditions also vary with ambient temperatures and species (Saxby et al. 2003; Rodolfo-Metalpa et al. 2008). Thus, understanding of physiological process of corals at low aragonite saturation states and low light conditions as well as at low temperature might lead to more accurate and realistic projections for the poleward expansion of coral habitats.

In conclusion, a consideration of the effect of the interannual variation of SST in the coldest months on coral mortality led to good correspondence between the simulated and observed timing and speeds of the poleward expansion of habitats for the tropical-subtropical coral species A. muricata and the subtropical-warm temperate species A. solitaryensis. Therefore, to simulate a more realistic poleward expansion, we need to consider the effect of the inter-annual variation of seawater temperature in winter on coral mortality, rather than the decadal-mean variation as used in previous studies.

Acknowledgments This work was stimulated by a discussion with Akio Takenaka. We thank the World Climate Research Programme's Working Group on Coupled Modeling, which is responsible for the CMIP. Thanks are extended to the climate-modeling group for producing and making available the MIROC4h output. For the CMIP, the US Department of Energy's Program for Climate Model Diagnosis and Intercomparison provided coordinating support and led the development of software infrastructure in partnership with the Global Organization for Earth System Science Portals. The monitoring of corals and SSTs was conducted by the "Monitoring Sites 1000" program of Japanese Ministry of the Environment and the "Monitoring for Global Warming Effects on Marine Environment" program of the Center for Global Environmental Research, National Institute for Environmental Studies. Additional SST data were provided by Keiichi Nomura and Tomoki Sunobe. We thank the editors and three anonymous reviewers for providing valuable comments that improved the manuscript significantly. This work was conducted under the framework of the "Precise Impact Assessments on Climate Change" of the Program for Risk Information on Climate Change (SOUSEI Program) supported by the Ministry of Education, Culture, Sports, Science, and Technology in Japan (MEXT).

Open Access This article is distributed under the terms of the Creative Commons Attribution 4.0 International License (http://creative commons.org/licenses/by/4.0/), which permits unrestricted use, distribution, and reproduction in any medium, provided you give appropriate credit to the original author(s) and the source, provide a link to the Creative Commons license, and indicate if changes were made.

\section{References}

Allouche O, Tsoar A, Kadmon R (2006) Assessing the accuracy of species distribution models: prevalence, kappa and the true skill statistic (TSS). J Appl Ecol 43:1223-1232

Donner SD (2009) Coping with commitment: projected thermal stress on coral reefs under different future scenarios. PLoS One 4:e5712

Donner SD, Knutson TR, Oppenheimer M (2007) Model-based assessment of the role of human-induced climate change in the 2005 Caribbean coral bleaching event. Proc Natl Acad Sci USA 104:5483-5488

Feely RA, Doney SC, Cooley SR (2009) Ocean acidification: present conditions and future changes in a high- $\mathrm{CO}_{2}$ world. Oceanography $22: 36-47$

Hoegh-Guldberg O, Fine M (2004) Low temperatures cause coral bleaching. Coral Reefs 23:444

Hoegh-Guldberg O, Fine M, Skirving W, Johnstone R, Dove S, Strong A (2005) Coral bleaching following wintry weather. Limnol Oceanogr 50:265-271

Harii S, Omori M, Yamakawa H, Koike Y (2001) Sexual reproduction and larval settlement of the zooxanthellate coral Alveopora japonica Eguchi at high latitudes. Coral Reefs 20:19-23

Harriott VJ, Smith SDA, Harrison PL (1994) Patterns of coral community structure of subtropical reefs in the Solitary Islands Marine Reserve, Eastern Australia. Mar Ecol Prog Ser 109:67-76

Harriott VJ, Harrison PL, Banks SA (1995) The coral communities of Lord Howe Island. Mar Freshw Res 46:457-465

Hongo C, Kayanne H (2011) Key species of hermatypic coral for reef formation in the northwest Pacific during Holocene sea-level change. Mar Geol 279:162-177

Ishii M, Kosugi N, Sasano D, Saito S, Midorikawa T, Inoue HY (2011) Ocean acidification off the south coast of Japan: a result from time series observations of $\mathrm{CO}_{2}$ parameters from 1994 to 2008. J Geophys Res Oceans 116:C06022

Ito M, Morimoto A, Watanabe T, Katoh O, Takikawa T (2014) Tsushima Warm Current paths in the southwestern part of the Japan Sea. Prog Oceanogr 121:83-93

Japan Meteorological Agency (2013) Climate change monitoring report 2012. Japan Meteorological Agency, Tokyo 
Jueterbock A, Tyberghein L, Verbruggen H, Coyer JA, Olsen JL, Hoarau G (2013) Climate change impact on seaweed meadow distribution in the North Atlantic rocky intertidal. Ecol Evol 3:1356-1373

Katoh O (1994) Structure of the Tsushima Current in the southwestern Japan Sea. J Oceanogr 50:317-338

Liu C, White M, Newell G (2011) Measuring and comparing the accuracy of species distribution models with presence-absence data. Ecography 34:232-243

McCulloch M, Falter J, Trotter J, Montagna P (2012) Coral resilience to ocean acidification and global warming through $\mathrm{pH}$ upregulation. Nat Clim Chang 2:623-627

Mezaki T, Hayashi T, Iwase F, Nakachi S, Nozawa Y, Miyamoto M, Tominaga M (2007) Spawning patterns of high latitude scleractinian corals from 2002 to 2006 at Nishidomari, Otsuki, Kochi, Japan. Kuroshio Biosphere 3:33-47 (in Japanese with English abstract)

Moberg F, Folke C (1999) Ecological goods and services of coral reef ecosystems. Ecol Econ 29:215-233

Moss RH, Edmonds JA, Hibbard KA, Manning MR, Rose SK, van Vuuren DP, Carter TR, Emori S, Kainuma M, Kram T, Meehl GA, Mitchell JFB, Nakicenovic N, Riahi K, Smith SJ, Stouffer RJ, Thomson AM, Weyant JP, Wilbanks TJ (2010) The next generation of scenarios for climate change research and assessment. Nature 463:747-756

Muir PR, Wallace CC, Done T, Aguirre JD (2015) Limited scope for latitudinal extension of reef corals. Science 348:1135-1138

Nojima S, Okamoto M (2008) Poleward range expansion and bleaching of corals. Nippon Suisan Gakaishi 74:884-888

Nomura K (2009) Recent changes in coral communities in Kushimoto, the southernmost part of Honshu, Japan. J Jpn Coral Reef Soc 11:39-49 (in Japanese with English abstract)

Nozawa Y, Harrison PL (2008) Temporal patterns of larval settlement and survivorship of two broadcast-spawning acroporid corals. Mar Biol 155:347-351

Nozawa Y, Tokeshi M, Nojima S (2006) Reproduction and recruitment of scleractinian corals in a high-latitude coral community. Amakusa, southwestern Japan, Mar Biol 149:1047-1058

Pernetta JC, Milliman JD (1995) Land-ocean interactions in the coastal zone: implementation plan. IGBP global change report 33, International Geosphere Biosphere Programme, Stockholm, Sweden

Reynolds RW, Smith TM, Liu C, Chelton DB, Casey KS, Schlax MG (2007) Daily high-resolution-blended analyses for sea surface temperature. J Clim 20:5473-5496

Rodolfo-Metalpa R, Huot Y, Ferrier-Pagès C (2008) Photosynthetic response of the Mediterranean zooxanthellate coral Cladocora caespitosa to the natural range of light and temperature. J Exp Biol 211:1579-1586

Sakamoto TT, Komuro Y, Nishimura T, Ishii M, Tatebe H, Shiogama H, Hasegawa A, Toyoda T, Mori M, Suzuki T, Imada Y, Nozawa T, Takata K, Mochizuki T, Ogochi K, Emori S, Hasumi H, Kimoto M (2012) MIROC4h - a new high-resolution atmosphere-ocean coupled general circulation model. J Meteorol Soc Jpn 90:325-359

Saxby T, Dennison WC, Hoegh-Guldberg O (2003) Photosynthetic responses of the coral Montipora digitata to cold temperature stress. Mar Ecol Prog Ser 248:85-97

Stocker TF, Qin D, Plattner G-K, Tignor M, Allen SK, Boschung J, Nauels A, Xia Y, Bex V, Midgley PM (2013) Climate change 2013: the physical science basis. Contribution of Working Group I to the Fifth Assessment Report of the Intergovernmental Panel on Climate Change. Cambridge University Press, Cambridge, United Kingdom and New York, NY, USA

Sugihara K, Sonoda N, Imafuku T, Nagata S, Ibusuki T, Yamano H (2009) Latitudinal changes in hermatypic coral communities from west Kyushu to Oki Islands in Japan. J Jpn Coral Reef Soc 11:51-67 (in Japanese with English abstract)

Sugihara K, Nomura K, Yokochi H, Shimoike K, Kajiwara K, Suzuki G, Zayasu Y, Dewa N, Fukami H, Kitano YF, Matsumoto H, Mezaki T, Nagata H, Tachikawa H, Kimura T (2015) Zooxanthellate scleractinian corals of Tanegashima Island, Japan. Center for Environmental Biology and Ecosystem Studies, National Institute for Environmental Studies, Tsukuba

Sugisaki H, Nonaka M, Ishizaki S, Hidaka K, Kameda T, Hirota Y, Oozeki Y, Kubota H, Takasuka A (2010) Status and trends of the Kuroshio region, 2003-2008. In: McKinnell SM, Dagg MJ (eds) Marine ecosystems of the north Pacific Ocean, 2003-2008. PICES Special Publication 4, pp 330-359

Sunday JM, Bates AE, Dulvy NK (2012) Thermal tolerance and the global redistribution of animals. Nat Clim Chang 2:686-690

Takao S, Kumagai NH, Yamano H, Fujii M, Yamanaka Y (2015) Projecting the impacts of rising seawater temperatures on the distribution of seaweeds around Japan under multiple climate change scenarios. Ecol Evol 5:213-223

Taylor KE, Stouffer RJ, Meehl GA (2012) An overview of CMIP5 and the experiment design. Bull Am Meteorol Soc 93:485-498

Teneva L, Karnauskas M, Logan CA, Bianucci L, Currie JC, Kleypas JA (2012) Predicting coral bleaching hotspots: the role of regional variability in thermal stress and potential adaptation rates. Coral Reefs 31:1-12

van Hooidonk R, Maynard JA, Planes S (2013) Temporary refugia for coral reefs in a warming world. Nat Clim Chang 3:508-511

van Hooidonk R, Maynard JA, Manzello D, Planes S (2014) Opposite latitudinal gradients in projected ocean acidification and bleaching impacts on coral reefs. Glob Chang Biol 20:103-112

van Vuuren DP, Edmonds J, Kainuma M, Riahi K, Thomson A, Hibbard K, Hurtt GC, Kram T, Krey V, Lamarque J-F, Masui T, Meinshausen M, Nakicenovic N, Smith SJ, Rose SK (2011) The representative concentration pathways: an overview. Clim Change 109:5-31

van Woesik R (1995) Coral communities at high latitude are not pseudopopulations: evidence of spawning at $32^{\circ} \mathrm{N}$, Japan. Coral Reefs 14:119-120

Veron JEN, Minchin PR (1992) Correlations between sea surface temperature, circulation patterns and the distribution of hermatypic corals of Japan. Cont Shelf Res 12:835-857

Yamano H, Namizaki N (2009) Corals on the front: changes of Acropora solitaryensis colonies at Tateyama, Chiba Prefecture, Japan. J Jpn Coral Reef Soc 11:71-72 (in Japanese)

Yamano H, Sugihara K, Nomura K (2011) Rapid poleward range expansion of tropical reef corals in response to rising sea surface temperatures. Geophys Res Lett. doi:10.1029/2010GL046474

Yamano H, Sugihara K, Watanabe T, Shimamura M, Hyeong K (2012) Coral reefs at $34 \mathrm{~N}$, Japan: exploring the end of environmental gradients. Geology 40:835-838

Yara Y, Fujii M, Yamanaka Y, Okada N, Yamano H, Oshima K (2009) Projected effects of global warming on coral reefs in seas close to Japan. J Japan Coral Reef Soc 11:131-140 (in Japanese with English abstract)

Yara Y, Oshima K, Fujii M, Yamano H, Yamanaka Y, Okada N (2011) Projection and uncertainty of the poleward range expansion of coral habitats in response to sea surface temperature warming: a multiple climate model study. Galaxea 13:11-20

Yara Y, Vogt M, Fujii M, Yamano H, Hauri C, Steinacher M, Gruber N, Yamanaka Y (2012) Ocean acidification limits temperatureinduced poleward expansion of coral habitats around Japan. Biogeosciences 9:4955-4968

Yara Y, Fujii M, Yamano H, Yamanaka Y (2014) Projected coral bleaching in response to future sea surface temperature rises and the uncertainties among climate models. Hydrobiologia 733:19-29 